\title{
LA SIERRA, LA CIUDAD Y LOS CICLOS DE LA REVOLUCIÓN
}

ROBERT CURLEY

Universidad de Guadalajara

\begin{abstract}
Uiero comentar brevemente tres aspectos de la obra de La revolución mexicana de Alan Knight, relacionando su enorme síntesis nacional con los procesos históricos de Jalisco. El primero tiene que ver con los tiempos y en particular con el carácter serrano de la revolución; el segundo, con la revolución de 1915 y las diferencias entre villismo y carrancismo; y el tercero con la última parte de su historia, enfocada en la formación, carácter y política del nuevo régimen. La selección de temas refleja mi lectura y los argumentos en mi opinión más importantes. Así, trato de entablar un diálogo con el trabajo del Dr. Knight desde la perspectiva de mi estado adoptivo y mi trabajo de investigación.

Es una empresa particularmente interesante, desde luego, por el lugar que ocupa el estado en la historiografía sobre el proceso revolucionario. Por una parte,
\end{abstract}

Jalisco fue de los estados que vieron una actividad revolucionaria decididamente menor que el norte o el territorio zapatista durante la segunda década del siglo. Por otra parte, fue cuna de la rebelión cristera durante los veinte. Hasta la fecha no existe un estudio para Jalisco que explique -satisfactoriamente- esta paradoja de los tiempos y las razones por las que los pueblos deciden -0 no- rebelarse.

Al abordar la revolución maderista, Knight nos advierte de las diferencias que matizan la dispersión de revueltas que fueron generando un movimiento por extensión nacional entre los últimos de 1910 y mediados del siguiente año. La revolución maderista se constituyó mediante una multitud de rebeliones, al principio sin coordinación. Sus diferencias son muchas: de clase, urbana /rural, de región, sierra /valle, sentimientos particulares/lógica política. Se trata de distinguir entre 
el ejército, la guerrilla y el foco; la nación se erige frente a la provincia y las revueltas agrarias frente a la paz industrial. Dentro de este mar de diferencias, Knight distingue tendencias: se presentan, particularmente en el norte, los atributos clásicos de una revolución popular; predominan temas locales y elementos rurales; el contenido es agrario; se imponen cambios políticos desde abajo, valiéndose a menudo de la violencia; la xenofobia ocupa un lugar secundario. ${ }^{1}$ Sin embargo, nos insta a distinguir la forma y origen de los movimientos, advirtiendo que los orígenes, aunque similares, pueden dar lugar a movimientos distintos en forma. Así, lejos del Norte, la revuelta popular, ejemplificada por el zapatismo de inicios, se repite -no sin matices- en Tlaxcala, la Huasteca, Ciudad del Maíz, Sinaloa, el Yaqui y el Mayo.

La revolución popular serrana que Knight ha tipificado para la Sierra Madre Occidental se extiende por Chihuahua, Durango y Zacatecas; luego se desvanece en suelo jalisciense. Sin embargo, los serra-

1. Pese a esta última afirmación, Knight observa que la violencia anti-extranjera fue diferenciada; generalmente dirigida contra los dueños de tiendas que surtían artículos de primera necesidad, los españoles y los chinos fueron proporcionalmente más afectados por la violencia de las turbas que los estadounidenses o los ingleses. nos que describe Knight se aproximan a una parte considerable de la población rural de Jalisco. Los distritos mineros del noroeste del estado (Etzatlán, Hostotipaquillo), las orillas de la Sierra Volcánica Transversal hacia Ciudad Guzmán en el sur y los Altos del noreste jalisciense tenían poblaciones rurales que pastoreaban, producían para subsistencia y mercado, y mantenían cierta autonomía frente a los centros de poder. Para 1910 parecían ser menos pobres y estar más firmemente integradas a los mercados y centros de poder político que las comunidades serranas del norte. Parecían gozar un mayor margen de gobierno local y menor presión sobre las tierras.

Knight ubica una tendencia hacia el bandolerismo en los movimientos serranos, advirtiendo la importancia de establecer cuándo los llamados bandidos obraban con apoyo popular entre los pueblos y cuándo no. El bandolerismo social de Hobsbawm, nos dice, es un modelo viable pese a su tendencia a romantizar el fenómeno. La clave, observa Knight, es la contingencia. El bandido social era distinto a otro por circunstancia más que por elección. En Jalisco, cuando las circunstancias favorecieron las revueltas rurales (a partir de 1913 y a través de 1917), las regiones serranas del estado se volvieron zonas de bandidaje, tanto de la variedad social co- 
mo de la variedad predatoria. Como en el caso de Pedro Zamora, los movimientos con arraigo popular a veces terminaban por desintegrarse entre violencia esporádica y oportunista.

Guadalajara quedaba al otro extremo de la serranía rural de Jalisco. Ciudad mercantil y administrativa del Occidente desde el siglo XviII, en 1910 era un moderno polo político que gozaba de cierta autonomía frente a la ciudad de México. Pese a la integración y progreso finisecular, en Guadalajara era patente la tensión entre una dinámica de provincia y otra nacional. Los motivos de los citadinos eran distintos a los de los serranos, pero con frecuencia la actitud era similar: No toleraban imposiciones de fuera. Luego de varios años de contienda revolucionaria, Guadalajara emergía como un centro de parroquialismo, opuesto a las grandes pretensiones universalistas y centralizadoras del estado nacional; su oposición política se articularía en torno al Arzobispado y a las organizaciones del catolicismo social.

JALISCO Y LOS REVOLUCIONARIOS DE 1915

Aun cuando Jalisco permaneció al margen de la revolución maderista, sus regiones serranas generaron movimientos con arraigo local luego del golpe de estado huertista. Inicialmente dispersos y contenidos, fue- ron transformados por el villismo de la Convención. Así, Jalisco se convirtió en un escenario importante de la guerra civil de 1915, entre fuerzas convencionistas de Villa y Julián Medina, y fuerzas constitucionalistas de Obregón y Manuel Diéguez. En este contexto, Knight argumenta que el estado de Jalisco era un premio mayor, al parecer disponible; y reflexiona sobre la inhabilidad villista de defender y gobernar el estado luego de desalojar las fuerzas de Diéguez. También apunta la capacidad extraordinaria con la que Diéguez logró ofender las sensibilidades locales, particularmente en Guadalajara donde (con Obregón) encarceló curas y permitió el saqueo de los templos que fueron convertidos en cuarteles.

No obstante los atropellos de Diéguez y la posterior debilidad militar de Medina (en ausencia de Villa), es importante apreciar que el gobierno militar de Diéguez gozó de un periodo de más de cinco meses (en 1914) sin amenazas villistas. Durante ese periodo, los revolucionarios ofendieron a muchos, pero también organizaron un gobierno, comenzaron a legislar medidas sociales mediante decreto, y buscaron con mayor claridad en términos del anticlericalismo desarrollista de los gobiernos de Diéguez y Bouquet. El secretario de Obras Públicas, encargado del proyecto de expropiación de la propiedad eclesiástica, es- 
cribía en su informe al gobernador que la religión no hacía más que adormecer los ánimos; que de la ciencia dependía el progreso de la humanidad. En su opinión, 32 de 54 templos católicos debieran ser usados para escuelas primarias, escuelas para adultos-obreros, museos, talleres de dibujo, confección y adiestramiento de artesanos. ${ }^{2}$

Aunque los sucesos de 1914-1917 desarticularon las organizaciones políticas y sociales-católicas, la política de la revolución en Jalisco, luego de las elecciones de 1917, provocó nuevos movimientos en defensa de la libertad religiosa. En.particular, el exilio forzado del arzobispo de Guadalajara (julio 1918 a febrero 1919) generó una movilización católica que cruzó diferencias de clase, sexo, etnicidad y generación, ubicando al Estado como enemigo común. Decenas de miles de católicos firmaban protestas que provenían de la capital y más de treinta ciudades secundarias y pueblos en todo el estado, incluyendo los municipios más importantes. Con mayor concentración en el corredor

2. La aplicación del artículo 130 en Jalisco se llamó Decreto 1913 y Decreto 1927. Limitaba la Iglesia a un templo y un sacerdote por cada 5,000 habitantes; establecía que los curas trabajarían sólo con licencia emitida por el estado; y que los infractores serían penados con uno a once meses de cárcel y multas de diez a doscientos pesos. central, los Altos y el sur del estado, hubo pocos municipios considerables que no protestaron (Ameca, Sayula, Atotonilco, Tepatitlán y Ocotlán).

La oposición católica de Guadalajara boicoteó al principal periódico del estado, obligándolo a cerrar. En toda la diócesis se observó un luto riguroso; las casas de miles de católicos tenían moños negros en las puertas y pancartas con la demanda de restaurar el orden en la ciudad y el estado. Knight ha observado que el carrancismo, con enfoque nacional, obraba a partir de una estrategia estadista, deseando minimizar los factores que no controlaba. Puede afirmarse, sobre todo para Guadalajara, que dicha actitud, y la experiencia de gobierno, les confirió una ventaja real a Diéguez y sus fuerzas.

Sobre los villistas Knight ha notado que predominaban elementos locales; bandidos, "bandidos sociales", rebeldes populares o alguna combinación. Estas fuerzas se aliaron con el villismo, algunas antes de la Convención, por lo menos nominalmente. Otras se aliaron cuando llegó Villa a Jalisco. Aunque eran genuinamente más tolerantes que los dieguistas -no eran sistemáticamente anticlericales ni anti-oligárquicas- tampoco lograron defender sus posiciones desde Guadalajara, ni lograron establecer un gobierno funcional. Aunque esto es cierto, hay que hacer 
notar que Medina sí intentó gobernar. Desde diciembre de 1914, y otra vez en febrero de 1915, cabildeaba para encontrar la manera de aplicar un impuesto que no fuera repudiado; buscaba estabilizar la moneda; y sobre todo, buscaba asegurar el abastecimiento de alimentos básicos. Coincido con Knight que es difícil conjeturar sobre la forma que hubiera tomado un gobierno villista. Pero en el caso de Jalisco me inclino a pensar que, a diferencia de Diéguez en 1914, Medina se vio limitado por la constante amenaza militar; más que por falta de un plan de gobierno, por incipiente que fuera, Medina trabajaba a la sombra de las fuerzas de Diéguez, en el sur del estado, y las de Murguía, que llegaron desde Michoacán.

\section{EL FANTASMA CARRANCISTA, SU POLITTCA}

\section{Y EL JALISCO CATÓLICO}

Los artículos 27 y 123 son indudablemente los más famosos de la Constitución de 1917. Sin embargo, se discutieron poco, dejando al historiador la inquietud de no saber hasta qué punto los constituyentes apreciaban el impacto que tendrían. En particular, el 123, que establece los derechos laborales, ha de haber parecido extraño a muchos, en medio de una revolución agraria, en un país rural con una fuerza de trabajo industrial aun incipien- te. Al contrario, los artículos más polémicos y debatidos fueron el $3^{\circ}, 5^{\circ}, 24$ y 130 , los que limitaban los derechos de la Iglesia Católica. En Jalisco, como en Querétaro, estos artículos se encontrarían en el centro de las pugnas políticas del nuevo régimen.

Knight comenta que los hombres del nuevo régimen correspondían, a grandes rasgos, a dos tipos ideales:

Uno, contaba en su ambiente con popularidad sustentada en antecedentes revolucionarios (militares), simpatía y cierta capacidad para relacionarse con la gente (la del campo sobre todo); el otro mostraba dominio más perspicaz de la realidad política nueva, nacional, de las posibilidades que tenían las reformas sociales (pensadas con perspectiva universal, no localista) y del poder del Estado que surgía. (vol. II, p. 1038)

Los líderes revolucionarios de Jalisco se caracterizaban por aquella visión universal, estadista, y aplicaban un proyecto de reformas sociales que atentaba directamente contra los intereses de la Iglesia, pero también contra las sensibilidades de una gran parte de la población.

Los sustentos ideológicos más importantes del nuevo régimen fueron un agrarismo oficial, nacionalismo capitalista en la economía, y un anticlericalismo que Knight denomina desarrollista. En Jalisco, el carácter del régimen -su ethos- se muestra parecido a lo que sucedió en Aguascalientes con los carrancistas. 
Los templos se cerraron y las prácticas religiosas se llevaron a cabo de manera clandestina en casas particulares. En Guadalajara la oposición se desplazaba de pie, boicoteando carros, carruajes y tranvía.

El Estado dio marcha atrás, derogando la legislación ofensiva. Para la Iglesia, y en particular las organizaciones sociales de jóvenes, mujeres y obreros, fue un triunfo importante. Estos grupos hacían política para ganar adeptos entre los grupos que el Estado consideraba propios. Así, observa Knight, la Iglesia no necesariamente amenazaba la revolución por oscurantista o reaccionaria, sino porque utilizaba las nuevas formas de movilización de masas, propias del carácter "revolucionario".

Quiero concluir donde concluye Alan Knight, preguntándome qué cambió con la revolución.

Recuerdo los apuntes iniciales de otro gran historiador, John Womack, en el capí- tulo con el que contribuyó a la Cambridge History of Latin America. Por importantes que hayan sido los movimientos populares de la revolución, más importante fue su derrota. Se trata menos de la revolución social, que de la administración política: tenacidad capitalista en la economía y reforma burguesa de la sociedad. Knight llega a conclusiones parcialmente similares. Se pregunta si la revolución destruyó la sociedad porfiriana, o si más bien la adaptó. La respuesta que nos deja no es de blanco y negro, ni tampoco podemos afirmar que en la obra de Knight la importancia fundamental está en lo político sobre lo social, ni en lo económico sobre lo cultural. Son elementos superpuestos en un complejo juego de circunstancias. En el mejor de los casos -y esto es lo que más frustra a mis alumnos en Guadalajarareconocemos que la revolución de Knight es demasiada compleja para ofrecer respuestas únicas. 